Original Research

\title{
Leader Empowering Behaviors and Psychological Empowerment as Perceived by Young Hospital Staff Nurses: A Pilot Study
}

\section{Ryan Michael Flores Oducado}

West Visayas State University, College of Nursing, Philippines

\begin{abstract}
Introduction: Empowerment has become an important concept in nursing that has gained acknowledgment in theories and practice of leadership and management. A positive organization espouses empowerment to attract and retain employees. While it is not new to nursing, there is little published research on empowerment among nurses in the Philippines. This study aimed to measure young staff nurses' perception of leader empowering behaviors and psychological empowerment.
\end{abstract}

Methods: This study used a cross-sectional survey design participated by 44 conveniently chosen staff nurses in a private teaching and training hospital in Iloilo City, Philippines. The participants were asked to answer 5-point Likert scale questions utilizing adopted instruments. Descriptive and non-parametric statistical stools were used with Mann-Whitney $U$ test to determine differences and Spearman's rank correlation to establish relationship between variables.

Results: Overall, young staff nurses perceived their leaders' behaviors to be highly empowering $(M=3.89)$. Staff nurses also had a high level of psychological empowerment ( $\mathrm{M}=4.07)$. Leader empowering behaviors was significantly related to staff nurses' perception of psychological empowerment ( $\mathrm{p}=.001)$. Staff nurses' level of psychological empowerment were significantly different in terms of employment status $(\mathrm{p}=.020)$ and years of work experience $(\mathrm{p}=.014)$.

Conclusion: This study highlights the positive influence of the empowering behaviors of leaders in enhancing staff nurses' level of psychological empowerment. It is vital for nurse managers to continually demonstrate leadership behaviors that empower staff nurses at the unit level.

\section{ARTICLE HISTORY}

Received: August 29, 2019

Accepted: October 09, 2019

\section{KEYWORDS}

empowerment; leadership; psychological empowerment; leader empowering behaviors; nursing empowerment

\section{CONTACT}

Ryan Michael Flores Oducado $\triangle$ rmoducado@wvsu.edu.ph $\fallingdotseq$ West Visayas State University, College of Nursing, Philippines

Cite this as: Oducado, R. M.F. (2019). Leader Empowering Behaviors and Psychological Empowerment as Perceived by Young Hospital Staff Nurses: A Pilot Study. Jurnal Ners, 14(1), 47-54. doi:http://dx.doi.org/10.20473/jn.v14i1.15056

\section{INTRODUCTION}

Empowerment has become a focal concept in nursing. Nursing empowerment is regarded as essential in ensuring professional success and in developing the professional image of nurses (Lockhart, 2017). Historically, nurses were viewed as submissive and dependent on the patriarchal medical hierarchy having little involvement in decisions affecting their practice standards (Okuyama, Wagner, \& Bijnen, 2014; Lockhart, 2017). However, the nursing profession has changed over the past decades. Today's healthcare environment calls for a more empowered nursing profession. In a multidisciplinary healthcare setting, even staff nurses are now encouraged to get involved in clinical and organizational decision-making processes (Van
Bogaert, Peremans, de Wit, Van Heusden, Franck, Timmermans, \& Havens, 2015). With the growing demands in the nurse manager's role in today's healthcare environment, the manager's ability to engage in empowering leadership behavior becomes a challenge (Greco, Laschinger, \& Wong, 2006; Lee \& Kim, 2013).

The nursing literature flourishes with studies on empowerment indicating that nursing empowerment is associated with less burnout, higher workplace satisfaction, commitment, increased autonomy, positive work behaviors and environment, better performance and patient health outcomes (Greco, Laschinger, \& Wong, 2006; Laschinger, Gilbert, Smith \& Leslie, 2010; Leggat, Bartram, Casimir \& Stanton, 2010; Jordan \& Davis 2013; Oyeleye, Hanson, 
O'Connor \& Dunn, 2013; Asiri, Rohrer, Al-Surimi, Da'ar, \& Ahmed, 2016; Goedhart, van Oostveen, \& Vermeulen, 2017). Empowered nurses are more likely to subscribe to more positive work practices resulting in positive patient outcomes (Donahue, Piazza, Griffin, Dykes \& Fitzpatrick, 2008). Correspondingly, the empowerment of nurses appears essential in the delivery of high-quality patient care (Goedhart, van Oostveen, \& Vermeulen, 2017). On the other hand, disempowered or powerless nurses are ineffective, unproductive and dissatisfied nurses (Manojlovich, 2007; Lee \& Kim, 2013; Mariano, Javier, Fauni, \& De Vera, 2014). In other words, powerless nurses are less likely to deliver the best possible care for their patients.

Despite the numerous positive benefits of empowerment, surveys reveal that nurses are still not sufficiently empowered. For instance, only a moderate level of empowerment was disclosed among staff nurses in the Philippines (Mariano, Javier, Fauni, \& De Vera, 2014) and Canada (Greco, Laschinger, \& Wong, 2006). Even among the nurse managers cohort in the United States, many were not fully empowered (Regan \& Rodriguez, 2011; Oliver, Gallo, Griffin, White, \& Fitzpatrick, 2014). This is critical because a leader must be empowered so that they can empower others (Regan \& Rodriguez, 2011). The nurse leader's empowering behaviors can be pivotal on how nurses perceive and respond to their work environment (Greco, Laschinger, \& Wong, 2006).

In this sense, nurse supervisors and managers have an essential role in empowering staff (Regan \& Rodriguez, 2011). Empowering staff is a vital nursing leadership function to cultivate a culture of productive work environment that encourages and sustains quality and safe patient care (Kramer, Schmalenberg \& Maguire, 2010; Asiri, Rohrer, AlSurimi, Da'ar, \& Ahmed, 2016). Nevertheless, nurses may feel powerless relative to organizational administrators and medical staff (Manojlovich, 2007). As empowerment of staff nurses can emerge from nursing leadership (Wilson and Laschinger, 1994), it is necessary to assess leadership behaviors that promote empowerment among staff. According to Kanter's (1993) theory of structural empowerment, opportunity, and power in organizations are essential to empowerment that contributes to getting the work done. Kanter (1993) described access to information, resources, support, and having a chance for advancement or opportunity to be involved in activities beyond one's job description as the main components of structural empowerment. Although not explicitly mentioned, the essence of structural empowerment or behaviors that lead an individual to act in an empowered manner has also been linked with nursing leadership, participative management and staff involvement in decision making (Kramer \& Schmalenberg, 1993; Upenieks, 2003; Linnen \& Rowley, 2014). This proposes that leadership behaviors can be sources of power in the work setting that enable staff to act or feel empowered. Given the ability of managers to affect the job responsibilities of their workforce, managers are likely to influence the task perceptions of their staff (Konczak, Stelly, \& Trusty, 2000). Konczak, Stelly, \& Trusty (2000) identified six dimensions of leader empowering behaviors: delegation of authority, accountability, self-directed decision-making, information sharing, skills development, and coaching for innovative performance. The leader's ability to exhibit and showcase these empowering actions will have an impact on the way staff will perceive the tasks given to them by their leader (Mendes \& Stander, 2011).

Meanwhile, empowerment also being both a process and an outcome must be facilitated (Kettunen, Poskiparta, \& Liimatainen (2001). With the call for a multidisciplinary approach in healthcare, nurse managers must acquire leadership competencies that can generate an empowered workplace (Asiri, Rohrer, Al-Surimi, Da'ar, \& Ahmed, 2016). Having the necessary structures that promote empowerment, such as empowering leader behaviors, may result in a psychologically empowering experience among staff. Conger and Kanungo (1988) and furthered by Spreitzer (1995) viewed empowerment as an enabling process implying motivation through enhancing personal efficacy manifesting as a set of four cognitions: meaning, competence, self-determination, and impact, that are shaped by a work environment. Conger and Kanungo (1988) also characterized empowerment as a process that involves a manager sharing power with subordinates.

While empowerment is not a new concept to nursing, limited published studies are available regarding the topic of nurses' empowerment in the local setting. Moreover, with the current nurse staffing challenges experienced by hospital organizations, fostering elements of a positive organization (Mendes \& Stander, 2011), in this case an empowered workplace, is needed if hospitals want to attract and retain their staff nurses (Bester, Stander, \& van Zyl, 2015). The role of leadership is a dynamic one between the leader and followers (Peachey, 2002). Continuous assessment of nurses' empowerment levels at every stage of their nursing career is henceforth essential (Al-Dweik, Al-Daken, Abu-Snieneh, \& Ahmad, 2016). This study is an attempt to investigate the young staff nurses' perceptions of leader empowering behaviors and psychological empowerment within the Philippine context and whether there is a significant relationship between the two major variables.

\section{MATERIALS AND METHODS}

This study employed a descriptive, cross-sectional research survey design. The study was conducted in a private tertiary hospital categorized as training and teaching hospital in Iloilo City, Philippines. In coordination with the Nursing Service Office of the hospital, administrative and ethical clearances were sought before the actual survey. Data were gathered 
during the monthly In-service training activity of the Nursing Service Office. Those who attended the activity, available, and willing to participate during the conduct of the survey were included in the study. Forty-four (44) conveniently chosen young staff nurses, with age ranging from 21 to 38 years old with an average age of 27 (Median $=28$ ), consented and participated in the study. All staff nurses were with Bachelor's degree, with a mean year of work experience equal to 2.9 (Median $=1.5$ ) ranging from less than one year to 12 years. Informed consent was secured prior to the administration of questionnaires. The participants were ensured of their voluntary participation, including their rights to anonymity and confidentiality. A sealed envelope containing the selfadministered questionnaires and a demographic and work-related profile sheet was distributed to the participants. Participants were asked to return the sealed envelope without any identifiable information.

Data for this study were gathered using two adopted research instruments that have been found valid in healthcare: Spreitzer's (1995) Psychological Empowerment Scale and Konczak, Stelly \& Trusty's (2003) Leader Empowering Behavior Questionnaire. The Psychological Empowerment Scale is a 12-item scale with four dimensions: meaning, competence, self-determination, and impact having three items measuring each dimension. According to Spreitzer's (1995), these subscales combined create psychological empowerment.

The Leader Empowering Behavior Questionnaire is a 19-item scale, consisting of six subscales: delegation of authority, accountability, self-directed decision-making, information sharing, skill development, and coaching for innovative performance. Each dimension has three items except for information sharing having four items. The original instrument consisted of 17 items, but two items on information sharing were added by Bester, Stander, \& van Zyl (2015).

All items of both instruments were answerable using a 5-point Likert-type scale (1=strongly disagree, $5=$ strongly agree). Higher scores indicate a higher level of empowerment. Moreover, authors of both scales disclosed an acceptable reliability level $(\alpha>$.70). Permission to adopt the scales were secured from authors prior to use.

Descriptive statistics (frequency, percentage, mean, median, mean rank, rank) were utilized in describing the demographic and work-related profile of the participants. Means were employed to determine the level of empowerment. Scale items were summed and averaged to yield scores ranging from 1 to 5 wherein $1.00-2.33$ was considered low, 2.34 - 3.66 was moderate, and 3.67 - 5.00 was high level. Mann-Whitney U test was performed to test for differences while Spearman rho tested for the correlation between leader empowering behaviors and psychological empowerment. The result was significant if alpha was less than .05. The data were computed with the aid of SPSS version 23.

\section{RESULTS}

Table 1 shows that majority of nurses were female $(68.2 \%)$, single $(86.6 \%)$, with permanent status of employment $(68.2 \%)$, with more than one year of work experience in the hospital setting (68.2\%) and were assigned in Medical and Surgical Units (68.2\%).

Table 2 shows that overall, staff nurses perceive their leaders' behaviors to be highly empowering $(\mathrm{M}=3.89 ; \mathrm{SD}=.43)$. Among the six (6) subscales, ensuring accountability $(M=4.05$, Rank 1), skills development ( $M=4.03$, Rank 2), information sharing $(\mathrm{M}=3.95$, Rank 3) were the most used empowering leadership behaviors. These were followed by decision-making ( $\mathrm{M}=3.80$, Rank 4) and delegation $(\mathrm{M}=3.77$, Rank 5) and coaching for innovative performance (M=3.69, Rank 6).

It can also be gleaned in Table 2 that staff nurses generally had high perceptions of psychological empowerment ( $M=4.07 ; S D=.44)$. Meaning $(M=4.36$, Rank 1) had the highest mean score among the subscales followed by competence ( $M=4.07$, Rank 2), self-determination ( $M=4.01$, Rank 3) with impact $(\mathrm{M}=3.83$, Rank 4) having the lowest mean score.

Statistical analysis using Spearman rho correlation revealed a significant positive relationship ( $\mathrm{r}=.472 ; \mathrm{p}=.001)$ between staff nurses' perception of leader empowering behaviors and psychological empowerment.

Table 3 shows that leader empowering behaviors did not vary significantly according to sex $(p=.350)$, employment status $(\mathrm{p}=.919)$, marital status $(\mathrm{p}=.394)$; years of work experience (.622), and area of work assignment (.061). Likewise, there were no significant differences in the staff nurses' perception of psychological empowerment classified as to sex $(\mathrm{p}=.899)$; marital status ( $\mathrm{p}=.481)$; area of assignment $(p=.098)$. There were, however significant differences in the psychological empowerment of staff nurses when grouped according to employment status ( $p$ $=.020)$ and years of experience $(p=.014)$. Staff nurses with permanent employment status (Mean rank = 25.57) had a significantly higher level of psychological empowerment over those with

Table 1. Demographic and work-related profile of staff nurses

\begin{tabular}{lcc}
\hline \multicolumn{1}{c}{ Variables } & n & $\mathbf{\%}$ \\
\hline Sex & & \\
$\quad$ Male & 14 & 31.8 \\
$\quad$ Female & 30 & 68.2 \\
Marital status & & \\
$\quad$ Single & 39 & 86.6 \\
$\quad$ Married & 5 & 11.4 \\
$\quad$ Employment status & & \\
$\quad \quad$ Permanent & 30 & 68.2 \\
$\quad$ Contractual & 14 & 31.8 \\
$\quad$ Years of work experience & & \\
$\quad$ 1 year or less & 14 & 31.8 \\
$\quad$ More than 1 year & 30 & 68.2 \\
$\quad$ Area of assignment & & \\
$\quad$ Medical-Surgical Units & 30 & 68.2 \\
$\quad$ Specialty Units (ER, ICU, DR) & 14 & 31.8 \\
\hline
\end{tabular}


Table 2. Level of leader empowering behaviors and psychological empowerment and relationship between variables

\begin{tabular}{lcccc}
\hline \multicolumn{1}{c}{ Variables } & Mean & SD & Interpretation & Rank \\
\hline Leader Empowering Behaviors (Overall) & 3.89 & 0.43 & High & \\
Accountability & 4.05 & 0.57 & High & 1 \\
Skills Development & 4.03 & 0.55 & High & 2 \\
Information Sharing & 3.95 & 0.53 & High & 3 \\
Decision-making & 3.80 & 0.54 & High & 4 \\
Delegation & 3.77 & 0.56 & High & 5 \\
Coaching for Innovative Performance & 3.69 & 0.64 & High & 6 \\
Psychological Empowerment (Overall) & 4.07 & 0.44 & High & \\
Meaning & 4.36 & 0.61 & High & 1 \\
Competence & 4.07 & 0.52 & High & 2 \\
Self-determination & 4.01 & 0.51 & High & 3 \\
Impact & 3.83 & 0.55 & High & 4 \\
& Spearman $r=.472$ & $p$-value $=.001$ & & \\
\hline
\end{tabular}

Table 3. Differences in leader empowering behaviors and psychological empowerment

\begin{tabular}{lcc}
\hline \multicolumn{1}{c}{ Variables } & $\begin{array}{c}\text { Leader Empowering Behaviors } \\
\text { p-value }\end{array}$ & $\begin{array}{c}\text { Psychological Empowerment } \\
\text { p-value }\end{array}$ \\
\hline Sex & 0.350 & 0.899 \\
Employment status & 0.919 & 0.020 \\
Marital status & 0.394 & 0.481 \\
Years of experience & 0.622 & 0.014 \\
Area of assignment & 0.061 & 0.098 \\
\hline
\end{tabular}

contractual employment status (Mean rank = 15.93). Also, staff nurses with more than 1 year of work experience in the hospital (Mean rank $=26.73$ ) had a significantly higher level of psychological empowerment compared to those with at least one year or less work experience.

\section{DISCUSSION}

This study attempted to determine the level of leader empowering behaviors and psychological empowerment among young staff nurses in a private hospital in the Philippines. Nursing scholars view empowerment as either arising from the environment or developing from one's psychological state (Manojlovich, 2007). In this study, leadership behaviors exhibiting empowerment were considered a structure within the environment wherein these leader empowering behaviors serve as the basis of power or source of the sense of being empowered. On the other hand, psychological empowerment is the intrinsic or personal factor of one's sense of empowerment. Empowerment is viewed as a process by which a leader enables staff members to act (Ibrahim, Abo El-Magd, \& Sayed, 2014). Laschinger, Gilbert, Smith, and Leslie (2010) emphasized the role of nurse managers in providing conditions or appropriate structures to enable staff nurses to perform effectively within their work environments, thereby contributing to the achievement of goals of the organization. This study supports Kanter's (1993) theoretical propositions that when leaders are effective in using empowering behaviors, staff nurses feel empowered to take on the tasks in their workplace. Kanter (1993) argued that organizational structures within the workplace are a precursor in shaping the work experiences of staff members.
Consistent with prior studies, leader empowering behaviors was significantly related to staff nurses' psychological empowerment. This means that the higher is the nurse leader's empowering behaviors, the higher is the level of psychological empowerment experienced by staff nurses. In other words, staff nurses who believe that their nurse managers are providing them with the necessary information to get their work done, involving them in decision-making affecting their practice, sharing with them unit governance, developing their skills continually and making them accountable for their practice, are more likely than those who do not believe in their manager's abilities, to come together to as a high functioning team in the workplace. Konczak, Stelly \& Trusty's (2003) disclosed that psychological empowerment was significantly related to leader empowering behaviors and was found to mediate between two outcome variables: job satisfaction and organizational commitment. Similarly, Peachey (2002) also found a significant correlation between leader empowering behaviors and psychological empowerment in a study conducted in Canada. A similar result was obtained in an Asian country where nurse managers' leadership behaviors were directly related to psychological empowerment among nurses working in acute care hospitals in Japan (Kanai-Pak, 2009). Staff nurses' perceptions of empowerment in their work setting are magnified by their leaders' empowering behaviors. In this study, nurse managers' leadership behaviors were essential for staff nurses to feel supported and empowered (Greco, Laschinger, \& Wong, 2006).

This study also demonstrated a high level of leader empowering behaviors as perceived by young staff nurses. While all empowering behaviors of leaders in this study were rated high, the dimensions of decision-making, delegation, and coaching for 
innovative performance fell below the composite mean. In contrast, researchers in Canada revealed that staff nurses perceived their leaders' behaviors to be only somewhat empowering (Greco, Laschinger, \& Wong, 2006). Nurses in the study of Peachey (2002) also perceived their leaders were exhibiting low to moderate empowering behaviors. Compared to the two studies conducted abroad, a higher level of leader empowering behaviors was demonstrated in this study. With the appreciation of the positive effects of empowerment in the nursing profession, nurse managers may have started to recognize and showcase empowering leadership behaviors. Although Asiri, Rohrer, Al-Surimi, Da'ar, \& Ahmed (2016) found that most nurses in their study believed that their immediate nursing managers were not displaying the ideal level of transformational leadership behaviors wherein empowerment is central, local studies provide support of the empowering leadership style or behaviors among Filipino nurse managers. For example, Lamasan \& Oducado (2018) found that Filipino millennial nurse administrators consider their leadership to be empowering. Correspondingly, Filipino nurses in a tertiary hospital in the Philippines agreed that their nurse managers utilized transformational leadership styles (Lapeña, Tuppal, Loo, Abe, 2017). Even in a neighboring Asian country, transformational leadership was said to enhance employee empowerment among nursing staff in Malaysia (Choi, Goh, Adam \& Tan, 2016).

This study also found that young staff nurses have a high level of psychological empowerment. This is congruent with the findings of researchers in Egypt (Hashish, All, \& Mousa, 2018), revealing nurses with a high level of psychological empowerment. However, in contrast to what was demonstrated in this study, most of the literature suggests that registered nurses' psychological empowerment is only at a moderate level. These studies include nurses in the Philippines (Mariano, Javier, Fauni, \& De Vera 2014), Canada (Peachey, 2002), New Zealand (Connolly, Jacobs, \& Scott, 2018), Iran (Royan , Alikhani, Mohseni, Alirezaei, Khosravizadeh, \& Moosavi, 2017), China (Ouyang, Zhou, \& Qu, 2015), Riyadh, Saudi Arabia (Asiri, Rohrer, Al-Surimi, Da'ar, \& Ahmed, 2016) and even also in Egypt (Ibrahim, Abo El-Magd, \& Sayed, 2014). It is still noteworthy that nurses' psychological empowerment was relatively moderate to high level.

As to each subscale, the result of this study is similar to findings reported in prior studies conducted elsewhere, wherein meaning had the highest and impact had the lowest mean score among the four dimensions. The meaning dimension was reported to have the highest mean in earlier researches (Peachey, 2002; Lee, 2012; Mariano, Javier, Fauni, \& De Vera, 2014; Asiri, Rohrer, AlSurimi, Da'ar, \& Ahmed, 2016). The meaning dimension is the value of a work goal or purpose, judged in relation to an individual's ideals or standards (Thomas \& Velthouse, 1990). The result of the study indicates that leader empowering behaviors influence staff nurses' perception of the value that they put in their job. Moreover, the result may indicate that staff nurses form a satisfying connection with their job (Mariano, Javier, Fauni, \& De Vera, 2014).

On the other hand, the impact dimension was consistently noted to have the lowest mean score among the four aspects of psychological empowerment (Peachey, 2002; Lee, 2012; Asiri, Rohrer, Al-Surimi, Da'ar, \& Ahmed, 2016, Hashish, All, $\&$ Mousa, 2018). The dimension of impact refers to the degree to which an individual can influence strategic, administrative, or operating outcomes at work (Thomas \& Velthouse, 1990). While this was found to be high, staff nurses may still have hesitations over the degree of control or impact they have on certain strategic, administrative, and operating outcomes of their work attributed to their level in the organization. Younger staff nurses have less degree of official power and influence within the hierarchal structure of the organization. For instance, staff nurses were not highly involved in decision making when unit managers made resolutions in the areas of professional practice governance and leadership, support staff practice, and recruitment (Gatbonton, 2019). Though there are varying mean scores in the four dimensions of psychological empowerment, Sprietzer (1995) maintains that the interplay of these components produces an overall feeling of being psychologically empowered.

It is also significant to note that in this study, variation in staff nurses' perception of psychological empowerment was noted according to employment status. Staff nurses with permanent status in their workplace may feel more psychologically empowered compared to those whose employment status is not permanent. Insecurity in one's job can exist when nurses experience uncertainty or danger of job loss (Hashish, All, \& Mousa, 2018). Employment status was found to be a good predictor of employment security among nurses in the Philippines (Egcas, 2017). Having a permanent work employment status may give staff nurses a sense of security. It was earlier studied that psychological empowerment was negatively correlated with job insecurity (Hashish, All, \& Mousa, 2018).

Also, this study discovered that years of work experience was significantly related to psychological empowerment. This suggests that staff nurses having longer years of working in the hospital may have better access to empowering structures within the hospital work setting. Nurses may have learned to navigate themselves at assessing empowerment structures to accomplish their work goals over time (Peachey, 2002). In China, nurses' psychological empowerment was found to be significantly different in terms of age and length of service (Ouyang, Zhou, \& $\mathrm{Qu}, 2015)$. Contrastingly, findings in Egypt disclosed no relationship between years of experience and psychological empowerment (Ibrahim, Abo El-Magd, \& Sayed, 2014). 
While there was a small sample size, this study provides additional evidence of nurses' empowerment and addresses the dearth of scientific knowledge on empowerment in the Philippine setting. Also, this study contributes to the literature regarding the positive effects of empowerment among staff nurses by having empowering leaders. Despite its input to the body of knowledge, this study has its limitations opening doors for future inquiry. The small sample size limited the generalization of findings hence, conclusions are considered preliminary. The use of self-administered questionnaires in data collection constrained findings to the danger of self-report bias. The researcher recommends the need for further study to address methodological issues experienced in this study. Studies involving larger samples may be conducted in the future to validate the findings of the present investigation.

\section{CONCLUSION}

Empowerment has gained recognition and acceptance among nurses both in the nursing leader and staff role. In this study, leader empowering behaviors is significantly related to psychological empowerment. Young staff nurses perceived the behaviors of their leaders as highly empowering, enabling them to feel highly empowered. Nursing leaders play a substantial part in creating positive work environments influencing how staff nurses respond to their work. When nurse managers give staff nurses the opportunity to take more responsibility, provide access to relevant information to get their job done, delegate tasks, develop their skills to enhance staff performance, and when decision making is shared in the hands of those who practice at the bedside, positive outcome among staff is likely realized. The empowering actions of the leader build staff nurses' confidence that permits them to act autonomously. Likewise, these empowering practices increase staff nurses' chance of finding meaning and impact in their work. Nurse managers and leaders should continuously develop strategies that enhance staff nurses' perceptions of feeling empowered. They should foster the elements of a positive organization to ensure empowering conditions at work. Besides, cultivating empowerment in the nursing profession is vital and imperative.

\section{REFERENCES}

Al-Dweik, G., Al-Daken, L.I., Abu-Snieneh, H., \& Ahmad, M.M. (2016). Work-related empowerment among nurses: Literature review. International Journal of Productivity and Quality Management, 19(2), 168-186. https://doi.org/10.1504/IJPQM.2016.078885

Asiri, S.A., Rohrer, W.W., Al-Surimi, K., Da'ar, 0.0., \& Ahmed, A. (2016). The association of leadership styles and empowerment with nurses' organizational commitment in an acute health care setting: A cross-sectional study. BMC Nursing, 15. https://doi.org/10.1186/s12912-016-0161-7

Bester, J., Stander, M.W., \& van Zyl, L.E. (2015). Leadership empowering behaviour, psychological empowerment, organisational citizenship behaviours and turnover intention in a manufacturing division. SA Journal of Industrial Psychology, https://doi.org/10.4102/sajip.v41i1.1215

Choi, S.L., Goh, C.F., Adam, M.B.H. \& Tan, O.K. (2016). Transformational leadership, empowerment, and job satisfaction: The mediating role of employee empowerment. Human Resources for Health, 14(1), 73. https://doi.org/10.1186/s12960-0160171-2

Conger, J.A., \& Kanungo, R.N. (1988). The empowerment process: Integrating theory and practice. Academy of Management Review, 13(3), 471-482. https://doi.org/10.5465/amr.1988.4306983

Connolly, M., Jacobs, S., \& Scott, K. (2018). Clinical leadership, structural empowerment and psychological empowerment of registered nurses working in an emergency department. Journal of Nursing Management, 28(6), 881-887. https://doi.org/10.1111/jonm.12619

Donahue, M.O., Piazza, I.M., Griffin, M.Q., Dykes, P.C., \& Fitzpatrick, J.J. (2008). The relationship between nurses' perceptions of empowerment and patient satisfaction. Applied Nursing Research, 21(1), 2-7. https://doi.org/10.1016/j.apnr.2007.11.001

Egcas, R.A. (2017). Employment security of nurses: Baseline for a strategic human resource direction. Asia Pacific Journal of Multidisciplinary Research, 5(4), 39-47.

Gatbonton, R.R.G. (2019). Decisional involvement on work quality of nurses. Nursing and Palliative Care International Journal, 2(1), 21-27. doi:10.30881/npcij.00011

Goedhart, N.S., van Oostveen, C.J., \& Vermeulen, H. (2017). The effect of structural empowerment of nurses on quality outcomes in hospitals: A scoping review. Journal of Nursing Management, 25(3), 194-206. https://doi.org/10.1111/jonm.12455

Greco, P., Laschinger, H.K., \& Wong, C. (2006). Leader empowering behaviors, staff nurse empowerment and work engagement/burnout. Nursing Leadership, 19(4), 41-56. doi:10.12927/cjnl.2006.18599

Hashish, E.A.A., All, N.H.A., \& Mousa, A.A. (2018). Nurses' perception of psychological empowerment and its relationship to work engagement and job insecurity. Journal of Nursing Education and Practice, 8(9), 36-44. https://doi.org/10.5430/jnep.v8n9p36

Ibrahim, M., Abo El-Magd, M.H., \& Sayed, H.Y. (2014). Nurse's psychological empowerment and perceived autonomy in university and teaching hospitals at Menofia Governorate/Egypt. Journal of Nursing Education and Practice, 4(9), 59-68. https://doi.org/10.5430/jnep.v4n9p59 
Jordan, R., \& Davis, C. (2013). Are you empowered? Nursing Made Incredibly Easy, 11(2), 4. doi:10.1097/01.NME.0000426297.01571.5d

Kanai-Pak, M. (2009). Leadership behaviors that mitigate burnout and empower Japanese nurses (Doctoral Dissertation). The University of Arizona, Tucson, Arizona

Kanter, R.M. (1993). Men and women of the corporation. New York, NY: Basic Books, Inc.

Kettunen, T., Poskiparta, M., \& Liimatainen, L. (2001). Empowering counselling-a case study: Nursepatient encounter in a hospital. Health Education Research, 16(2), https://doi.org/10.1093/her/16.2.227

Konczak, L.J., Stelly, D.J., \& Trusty, M.L. (2000). Defining and measuring empowering leader behaviors: Development of an upward feedback instrument. Educational and Psychological Measurement, 60(2), 301-313. http://dx.doi.org/10.1177/00131640021970420

Kramer, M., \& Schmalenberg, C. (1993). Learning from success: Autonomy and empowerment. Nursing Management, 24(5), 58-64. DOI:10.1097/00006247-199305000-00012

Kramer, M., Schmalenberg, C., \& Maguire, P. (2010). Nine structures and leadership practices essential for a magnetic (healthy) work environment. Nursing Administration Quarterly, 34(1), 4-17. doi:10.1097/NAQ.0b013e3181c95ef4

Lamasan, J.I.L. \& Oducado, R.M.F. (2018). A qualitative description of millennial nurse administrators' perspectives on leadership and their practice environment. Indonesian Nursing Journal of Education and Clinic, 2(3), 153-164. http://dx.doi.org/10.24990/injec.v3i2.226

Lapeña, L.F.R., Tuppal, C.P., Loo, B.G.K., \& Abe, K.H.C. (2017). Transformational and transactional leadership styles of nurse managers and job satisfaction among Filipino nurses: A pilot study. Nurse Media Journal of Nursing, 7(2), 65-78. https://doi.org/10.14710/nmjn.v7i2.15171

Laschinger, H.K.S., Gilbert, S., Smith, L., \& Leslie, K. (2010). Towards a comprehensive theory of nurse/patient empowerment: Applying Kanter's empowerment theory to patient care. Journal of Nursing Management, 18(1), 4-13. https://doi.org/10.1111/j.13652834.2009.01046.x

Lee, E.S. (2012). Job satisfaction among staff nurses in relation to leader empowering behaviors, structural empowerment and psychological empowerment (Master's thesis). University of British Columbia, Vancouver, Canada. DOI: 10.14288/1.0166827

Lee, J.W., \& Kim, D.W. (2013). Mediating effects of psychological empowerment on the relationship between nurse's self leadership and organizational commitment. Health and Social Welfare Review, 33(2), 366-400. DOI:10.15709/hswr.2013.33.2.366

Leggat, S.G., Bartram, T., Casimir, G., \& Stanton, P. (2010). Nurse perceptions of the quality of patient care: Confirming the importance of empowerment and job satisfaction. Health Care Management Review, 35(4), doi:10.1097/HMR.0b013e3181e4ec55

Linnen, D., \& Rowley, A. (2014). Encouraging clinical nurse empowerment. Nursing Management, 45(2), 44-47. doi:10.1097/01.NUMA.0000442640.70829.d1.

Lockhart, L. (2017). Let's hear it for empowerment. Nursing Made Incredibly Easy, 15(4), 55. doi:10.1097/01.NME.0000520146.46175.68

Manojlovich, M. (2007). Power and empowerment in nursing: Looking backward to inform the future. OJIN: The Online Journal of Issues in Nursing, 12(1), Manuscript doi:10.3912/OJIN.Vol12No01Man01

Mariano, S.M.N., Javier, W.B., Fauni, L.L., \& De Vera, L.A. (2014). Level of empowerment of staff nurses in selected private hospitals in Cavite. Philippine Journal of Nursing, 84(2), 40-47.

Mendes, F., \& Stander, M.W. (2011). Positive organisation: The role of leader behaviour in work engagement and retention. SA Journal of Industrial Psychology, 37(1), 1-13. DOI: https://doi.org/10.4102/sajip.v37i1.900

Peachey, G.A. (2002). The effect of leader empowering behaviours on staff nurses workplace empowerment, psychological empowerment, organizational commitment, and absenteeism (Doctoral Dissertation). McMaster University, Hamilton, Canada

Oliver, B., Gallo, K., Griffin, M.Q., White, M., \& Fitzpatrick, J. (2014). Structural empowerment of clinical nurse managers. JONA: The Journal of Nursing Administration: 44(4), 226-231. doi: 10.1097/NNA.0000000000000059

Okuyama, A., Wagner, C., \& Bijnen, B. (2014). How we can enhance nurses' assertiveness: A literature review. Journal of Nursing Care, 3(5), 1-9. https://doi.org/10.4172/2167-1168.1000194

Oyeleye, O., Hanson, P., O’Connor, N., \& Dunn, D. (2013). Relationship of workplace incivility, stress, and burnout on nurses' turnover intentions and psychological empowerment. The Journal of Nursing Administration, 43(10), 536-542. doi:10.1097/NNA.0b013e3182a3e8c9

Ouyang, Y.Q., Zhou, W.B. \& Qu, H. (2015). The impact of psychological empowerment and organisational commitment on Chinese nurses' job satisfaction. Journal of Contemporary Nurse, 50(1), 80-91. https://doi.org/10.1080/10376178.2015.10102 53

Regan, L.C., \& Rodriguez, L. (2011). Nurse empowerment from a middle-management perspective: nurse managers' and assistant nurse managers' workplace empowerment views. The Permanente Journal, 15(1), e101-e107.

Royan, S., Alikhani, M., Mohseni, M., Alirezaei, S., Khosravizadeh, O., \& Moosavi, A. (2017) .Nurses' psychological empowerment in Iran: A systematic review and meta-analysis. Annals of Tropical 
R. M. F. ODUCADO ET AL.

Medicine and Public Health,10(6),1558-1562. DOI: 10.4103/ATMPH.ATMPH_509_17

Spreitzer, G.M. (1995). Psychological empowerment in the workplace: Dimension, measurement, and validation. The Academy of Management Journal, 38(5), 1442-1465. DOI: 10.2307/256865

Thomas, K.W., \& Velthouse, B.A. (1990). Cognitive elements of empowerment: An "interpretive" model of intrinsic task motivation. Academy of Management Review, 15, 666-681. DOI: $10.2307 / 258687$

Upenieks, V.V. (2003). The interrelationship of organizational characteristics of magnet hospitals, nursing leadership, and nursing job satisfaction.
Health Care Manager, 22(2), 83-98. DOI: 10.1097/00126450-200304000-00002

Van Bogaert, P., Peremans, L., de Wit, M., Van Heusden, D., Franck, E., Timmermans, O., \& Havens, D. S. (2015). Nurse managers' perceptions and experiences regarding staff nurse empowerment: A qualitative study. Frontiers in Psychology, 6 , 1585. doi:10.3389/fpsyg.2015.01585

Wilson, B., \& Laschinger, H.K.S. (1994). Staff nurses' perception of job empowerment and organizational commitment: A test of Kanter's theory of structural power in organizations. Journal of Nursing Administration, 24(4s), 39-45. 